\title{
LEITURA EM VOZ ALTA, VARIAÇÃO LINGUÍSTICA E O SUCESSO NA APRENDIZAGEM INICIAL DA LEITURA
}

\author{
Raquel Meister Ko. Freitag ${ }^{1 \times}$ \\ José Junior de Santana Sá ${ }^{1 * *}$ \\ ${ }^{1}$ Universidade Federal de Sergipe, São Cristóvão, SE, Brasil
}

Resumo

Em uma interface entre psicolinguística e sociolinguística, considerando o monitoramento estilístico (fala $\rightarrow$ atividades orais $\rightarrow$ leitura em voz alta) e as condições necessárias para a aprendizagem inicial da leitura na alfabetização, apresentamos os perfis de leitura de estudantes do $3^{\circ}$ ano do ensino fundamental e os relacionamos com o desempenho em um teste de compreensão leitora e com a ocorrência de traços variáveis da fala na leitura em voz alta. Os resultados evidenciam que a leitura em voz alta que apresenta traços variáveis da fala não pode ser considerada "imprecisa"; ao contrário, estes traços ocorreram somente na leitura hábil e palavra por palavra, e por estudantes que atingem níveis mais altos no teste.

Palavras-chave:Leitura em Voz Alta; VariaçãoLinguística;Sociolinguística.

\section{READING ALOUD: LINGUISTIC VARIATION AND THE SUCCESS IN READING EARLY LEARNING}

\section{Abstract}

In an interface between psycholinguistics and sociolinguistics, considering stylistic monitoring (speech $\rightarrow$ oral activities $\rightarrow$ reading aloud) and the necessary conditions for early literacy, this paper presents the reading profiles of $3^{\text {rd }}$ grade students from elementary school and relates them to performance on a reading comprehension test and to the occurrence of variable features of speech in reading aloud. The results show that the reading aloud which presents variable features of speech cannot be considered "inaccurate"; instead, these features occurred only in proficient and word-to-word types of reading, and only by students who reached higher levels on the test.

Key-words: Reading Aloud; Linguistic Variation; Sociolinguistics.

\footnotetext{
Doutora em Linguística pela Universidade Federal de Santa Catarina. Professora do Departamento de Letras Vernáculas e dos Programas de Pós-Graduação em Letras, Psicologia e Educação da Universidade Federal de Sergipe. Bolsista de Produtividade em Pesquisa do CNPq. Seu e-mail é: rkofreitag@uol.com.br. ORCID: https:// orcid.org/0000-0002-4972-4320.

"* Mestre em Educação pela Universidade Federal de Sergipe. Bolsista Capes. Seu e-mail é: juniorpfolha@ hotmail.com. ORCID: https://orcid.org/0000-0002-6714-133X.
} 


\section{Introdução}

Os resultados nacionais da Avaliação Nacional de Alfabetização (ANA) aplicada em 2016, distribuídos em uma escala de 4 níveis, apontam que 55\% dos alunos no $3^{\circ}$ ano do ensino fundamental demonstram conhecimentos insuficientes em leitura, o que corresponde aos níveis 1 e 2. Em Sergipe, este percentual chega a $75 \%$ dos estudantes avaliados. A ANA, como parte integrante do conjunto de avaliações de larga escala do Sistema de Avaliação da Educação Básica, tem como objetivo avaliar o sistema educacional. Por conta disso, a divulgação dos resultados, consolidados por instituição escolar, município e estado, não permite a realização de ações pedagógicas para corrigir a assimetria identificada entre o que é esperado e o que é aferido, seja por não identificar o estudante e a turma, seja por não haver tempo suficiente entre a realização do exame e a divulgação dos resultados. Isso significa que, em Sergipe, três em cada quatro estudantes que não atingiram o nível da suficiência irão continuar com este problema, gerando efeitos em cascata verificados nas outras avaliações oficiais e em retenção e evasão.

Além de explicar por que 75\% dos estudantes estão nos níveis 1 e 2, é preciso saber o que acontece com os $25 \%$ que atingiram os níveis 3 e 4 , que correspondem, respectivamente, à situação de proficiência adequada e desejável para esta fase. Neste artigo, assumindo uma interface conceitual e metodológica entre a psicolinguística e a sociolinguística para abordar um tema muito caro ao cenário brasileiro que é a aprendizagem da leitura, apresentamos resultados de um estudo desenvolvido em uma escola municipal de São Cristóvão, Sergipe, em que acompanhamos uma turma de $3^{\circ}$ ano durante o ano de 2017, documentando fala, participação em atividades orais, leitura em voz alta e aplicamos um teste de compreensão leitora (TCL) aos moldes da ANA. Pelo viés da psicolinguística, categorizamos os estudantes quanto ao seu perfil de leitura. Pelo viés da sociolinguística, consideramos o monitoramento estilístico envolvido nas atividades documentadas fala $\rightarrow$ atividades orais $\rightarrow$ leitura em voz alta, e observamos o comportamento de traços variáveis do sistema linguístico. Iniciamos retomando as condições necessárias para a aprendizagem inicial da leitura, conforme Morais et al (2013), a partir das quais apresentamos os perfis de leitura, com base na proposta de Ehri (1995). Em seguida, retomamos o conceito de precisão em leitura em voz alta de modo a contemplar as dimensões de rotas de leitura e consciência sociolinguística. Por fim, relacionamos o desempenho no TLC e a ocorrência de traços variáveis da fala na leitura em voz alta, cotejando ao perfil de leitura identificado, evidenciando que estudantes cuja leitura em voz alta que apresenta traços variáveis da fala tem perfil hábil e palavra por palavra, e atingem o nível esperado no TLC.

\section{Condições para a aprendizagem inicial da leitura na alfabetização}

A leitura mobiliza um conjunto de conhecimentos, capacidades e processos que são comuns à compreensão vinculada, principalmente, à fala, mas também à escrita: inclui conhecimento do léxico, da morfologia, da sintaxe e da semânti- 
ca, capacidade de raciocínio, atenção, memória de trabalho e memória de longo prazo, capacidades de análise e síntese. No entanto, aprender a ler é adquirir uma habilidade específica, a habilidade de reconhecimento das palavras escritas, cujo desenvolvimento é crucial para a aquisição do conhecimento e para o desenvolvimento cognitivo de modo geral, e envolve quatro níveis de processamento, interdependentes (SEIDENBERG; MCCLELLAND, 1989). No nível ortográfico, após a recepção visual das formas impressas, se dá o reconhecimento de padrões familiares de letras, com o processamento de todas as letras, que é pareado foneticamente com o processamento fonológico, que promove a ativação fonológica da palavra ("ouvir a palavra na cabeça"). No nível do processamento de significado, são ativados todos os sentidos possíveis para a palavra; e, no nível do processamento contextual, o significado é selecionado com base nas pistas contextuais. Nosso foco, neste texto, é o nível do processamento fonológico e ortográfico.

O reconhecimento envolve o acesso às informações na memória lexical de como a palavra é pronunciada e o seu significado. A evolução da aprendizagem da decodificação das palavras escritas envolve três condições - conhecimento do princípio alfabético; o conhecimento do código ortográfico da língua e o domínio do procedimento de decodificação; e a constituição do léxico mental ortográfico (MORAIS et al., 2013; MORAIS, 2013).

A primeira condição é o ponto de partida: a compreensão do princípio alfabético, ou princípio de correspondência entre fonemas e grafemas, ou seja, o entendimento de que a sequência de letras em uma palavra escrita representa a sequência de sons (fonemas) na palavra falada. Essa condição requer uma análise consciente da estrutura fonológica da fala combinada com a identificação de letras, com a criação de mapas ortográficos, conexões entre letras e sons, que ligam a grafia, a pronúncia e o significado das palavras na memória, com as palavras visuais, um repositório com todas as palavras lidas na memória.

Desenvolver a capacidade de reconhecimento da sequência das letras de uma palavra e o emparelhamento com os fonemas correspondentes são operações que intervêm no processo inicial da decodificação (FRITH et al. 1985, SEIDENBERG; MCCLELLAND, 1989; EHRI, 1995; BUCHWEITZ; MOTA; NAME, 2018). Dehaene (2012) considera essa condição decisiva, pois é nessa operação que se deve focalizar todos os esforços, as correspondências necessitam ser ensinadas explicitamente e sem receio de repetições, de modo a tornar o processo de associação entre grafemas e fonemas rápido, preciso e automático. Essa é a segunda condição, o conhecimento progressivo do código ortográfico da língua e o domínio dos procedimentos de decodificação.

Paralelo ao conhecimento do código ortográfico da língua e o domínio do procedimento de decodificação, se dá o desenvolvimento da constituição do léxico mental ortográfico, a terceira condição. Mapas ortográficos formam conexões entre as palavras lidas e padrões de sons, que ficam retidas na memória, possibilitando a automaticidade no processo de decodificação (EHRI, 2014). Estas representações estão relacionadas à nossa memória de longo prazo, e são acessadas automaticamente e sem nossa consciência dos processos que levam à identifica- 
ção das palavras (MORAIS et al. 2013), e são desenvolvidas gradualmente. Nesta perspectiva, Ehri (1995) propõe uma sequência de fases do desenvolvimento da leitura de palavras em direção à leitura hábil: pré-alfabética, baseada em pistas visuais incidentais; alfabética inicial, que pressupõe o reconhecimento de letras e o desenvolvimento parcial da consciência fonológica; alfabética intermediária, em que as primeiras palavras visuais são aprendidas, a correspondência grafema-fonema é automatizada e o desenvolvimento da consciência fonológica é completo; e alfabética consolidada, em que a leitura é fluente a partir do reconhecimento de padrões de sons (sílabas, prefixos, fonogramas), até a fase automática, com a leitura proficiente de palavras, que caracteriza o leitor hábil, ou proficiente. O leitor hábil domina as correspondências letra-som, utiliza várias estratégias para decodificar palavras e lê as palavras automaticamente. Por outro lado, o leitor que não desenvolveu plenamente as habilidades de leitura é aquele que depende do contexto ou de figuras para identificar palavras familiares e não familiares, eolha a primeira letra e tenta adivinhar a palavra. Logo no início do aprendizado e prática da leitura, algumas palavras curtas e frequentes já são lidas nesse modo automático e, aos poucos, isto vai acontecendo com várias outras palavras, "mas é geralmente no decurso do $3^{\circ}$ ano que o léxico ortográfico se torna o mecanismo dominante na leitura" (MORAIS et al. 2013, p. 23).

Ao alcançar a última, constituição do léxico mental ortográfico, os leitores direcionam sua atenção para a compreensão do texto. Uma habilidade se torna automática quando seu processamento se completa enquanto a atenção é direcionada para outra atividade (SHIFFRIN; SCHNEIDER, 1977; SCHNEIDER; CHEIN, 2003). No caso da leitura, a automaticidade é adquirida a partir do momento em que o leitor visualiza as palavras sem dedicar atenção ou esforço à decodificação e, imediatamente, reconhece suas pronúncias e seus respectivos significados. Isso é possível a partir de exposições sucessivas. A prática é o que leva à automaticidade; e a automaticidade estabelece rotas para a leitura.

\section{Rotas de leitura}

Da palavra escrita à leitura em voz alta há duas rotas: a fonológica e a lexical. As operações com a escrita começam desde o sistema visual, quando o olho, especificamente o centro da retina, chamado de fóvea, se desloca sobre a página e a cada pausa o leitor identifica os detalhes das letras do alfabeto, a posição de cada letra na palavra e faz seus devidos agrupamentos (DEHAENE, 2012).

A rota fonológica, segundo Coltheart (2013), diz respeito ao uso do conhecimento das regras que relacionam segmentos da ortografia com segmentos da fonologia (conversão grafema-fonema). Após ativar a representação ortográfica à sua forma fonológica, ocorre o acesso ao significado. Esta rota permite ler palavras não familiares e pseudopalavras, e garante precisão na leitura de palavras regulares, mas não de palavras irregulares.

Acessar a rota lexical significa procurar uma palavra em um léxico mental que contém conhecimento sobre as grafias e pronúncias de sequência de letras 
que formam palavras reais; a busca não ocorre no nível grafema-fonema, mas na palavra como um todo, permitindo o acesso a um dicionário mental onde está armazenado o significado das palavras (COLTHEART, 2013). Para explicar o que seria esse dicionário mental, Dehaene (2012, p.57) usa a metáfora que de "nosso cérebro abriga uma biblioteca em muitos volumes, desde o guia ortográfico até o manual de pronúncia e o grande dicionário enciclopédico".

Por meio da leitura em voz alta e a partir do modelo de dupla rota, Coltheart (2013, p. 33) verificou que:

a. Palavras de alta frequência são lidas em voz alta com mais rapidez do que palavras de baixa frequência.

b. Palavras são lidas em voz alta com mais rapidez do que não palavras.

c. Palavras regulares são lidas em voz alta com mais rapidez do que palavras irregulares.

d. O tamanho da vantagem da regularidade é maior para palavras de baixa frequência do que palavras de alta frequência.

A rota fonológica exerce um papel importante na aprendizagem inicial da leitura. As condições para a automaticidade da decodificação estão todas relacionadas a processos que envolvem o uso de tal rota. Para alcançar o nível automático da identificação das palavras escritas e usar a rota lexical, o leitor dependerá da repetição das operações conscientes da decodificação (MORAIS, 2013).

O leitor que faz uso da rota lexical já alcançou o nível hábil da leitura, pois ativa de modo inconsciente e automático as representações ortográficas, fonológicas e os significados das palavras armazenadas no seu léxico mental. Ele consegue reconhecer com maior rapidez palavras de alta frequência na língua. Para as palavras de baixa frequência, as que não fazem parte do seu léxico mental, o leitor usará a rota fonológica, que tem um papel crucial na decodificação de palavras novas. Desenvolver a capacidade de leitura pela rota lexical permite liberar recursos cognitivos e linguísticos para operar na análise sintática e na integração semântica levam à compreensão (MORAIS, 2014). A automaticidade e a precisão permitem identificar estágios do reconhecimento das palavras (SAMUELS, 1988): não acurado (com muitos erros de decodificação); acurado mas não automático (com poucos erros de decodificação, mas grande demanda de tempo, por uso de rota fonológica) e acurado e automático (com poucos erros de decodificação e pouca demanda de tempo, por uso de rota lexical).

A proposição de um modelo de rotas de leitura é uma construção teórica; na prática, não existem recursos para se medir como o leitor está lendo e que rotas está acessando. Nos valemos de evidências indiretas, como a precisão, a expressividade prosódica e a velocidade com que lê, o que nos dá perfis impressionísticos 
de leitor, como propõem Machado e Freitag (2019); a este conjunto de evidências, adicionamos a presença de traços variáveis da fala na leitura.

\section{Precisão na leitura e a variação linguística}

No modelo de rotas de leitura, um ponto importante a discutir é a relação entre rotas, variação linguística e a precisão da leitura. Assumindo a perspectiva da diversidade linguística, a presença da variação linguística na leitura não pode ser considerada erro, mas sim pista de acesso à rota lexical e, por conseguinte, da automaticidade na decodificação, um requisito da leitura.

Um dos parâmetros para avaliar o aprendizado da leitura é a precisão na leitura em voz alta, entendida como a habilidade de decodificar a palavra escrita corretamente (RASINSKI, 2004). Para precisão de leitura, é necessário conhecer o sistema alfabético e das relações de transparência do sistema ortográfico do português, além de um amplo vocabulário da língua (palavras frequentes). No entanto, se o processo de alfabetização se resumisse à conversão unívoca de fonemas a grafemas, o trabalho do professor seria muito mais simples: as normas ortográficas não obedecem ao input ao qual a criança está exposta, à sua variedade linguística. As contribuições da Sociolinguística precisam integrar de forma mais acentuada a formação de professores-alfabetizadores e devem mediar o processo de aprendizagem inicial da leitura (FREITAG, 2015). Os pressupostos de leitura dos Parâmetros Nacionais de Língua Portuguesa (PCN), que preveem o trabalho com textos e com o reconhecimento do vernáculo dos estudantes. O trabalho com a variação linguística está previsto nos PCN, quando preconizam "conhecer e respeitar as diferentes variedades linguísticas do português falado" (BRASIL, 2000 , p. 41), reconhecendo os fenômenos variáveis da fala dos estudantes. $\mathrm{Na}$ Base Nacional Comum Curricular também está previsto, nas competências para o ensino de Língua Portuguesa para o ensino fundamental, "compreender o fenômeno da variação linguística, demonstrando atitude respeitosa diante de variedades linguísticas e rejeitando preconceitos linguísticos" (BRASIL, 2017, p. 85).

A automaticidade na decodificação da palavra escrita sem esforço cognitivo ou atenção é uma habilidade essencial na precisão de leitura (LABERGE; SAMUELS, 1974, FUCHS et al, 2001). Na leitura em voz alta, o modelo da dupla rota permite identificar o processo cognitivo na decodificação da palavra que contribui para a precisão na leitura. $\mathrm{Na}$ abordagem das rotas de leitura, a precisão tem sido medida pela identificação de erro de decodificação da palavra (COLTHEART, 2013). No entanto, considerando o acesso à rota lexical, identificamos a transposição de fenômenos variáveis da fala na leitura em voz alta em palavras de alta frequência (PINHEIRO et al, 2008; AQUINO, 2011; MACHADO, 2018). Por ter já a representação da palavra visual (EHRI, 1995), o leitor que faz uso dessa rota já conhece a palavra escrita e pode oralizá-la, conforme seu repertório linguístico, com maior precisão e rapidez. Quando o estudante lê pa/y/aço em vez de $p a /$ K/aço não apresenta erro, mas um fenômeno variável da fala espontânea transposto para a leitura em voz alta. 
Desenvolver a habilidade da precisão é necessário para a fluência em leitura oral, uma vez que a baixa precisão no reconhecimento da palavra escrita influencia de forma negativa na compreensão do texto; a sensibilidade sociolinguística pode auxiliar neste processo (LABOV, 2003). A relação com aspectos sociolinguísticos e problemas de leitura não é novidade: está presente desde Language in the inner city, em que Labov (1972) apresenta os efeitos sociais da variação na língua, cultura, organização social e a situação política dos jovens negros na periferia das cidades americanas nos anos 1960. Assim como hoje no Brasil, à época, falhas na proficiência em leitura eram claramente óbvias nas escolas de Nova Iorque, segundo Labov (1972). A questão norteadora da investigação foi justamente buscar uma explicação nas diferenças dialetais: desconhecimento das regras do inglês padrão por parte dos falantes do inglês não padrão e desconhecimento das regras do inglês não padrão por parte dos professores e autores de textos.

No cenário sociolinguístico brasileiro, Bortoni-Ricardo explora as diferenças entre as variedades considerando traços graduais e descontínuos. Os traços descontínuos da fala são mais característicos da variedade linguística dos polos rurais; "esses traços têm uma distribuição descontínua porque seu uso é 'descontinuado' (BORTONI-RICARDO, 2004, p. 53) nas áreas urbanas", são traços estigmatizados socialmente e recebem avaliação negativa nas comunidades urbanas (como a vocalização). Há também outros traços que estão presentes na fala de quase todos os brasileiros, e esses são chamados de graduais (como monotongação, ditongação, apagamento do /R/ em coda silábica). A presença destes traços graduais na leitura sugere não erro de precisão, mas sim o acesso da rota lexical, ao invés da rota fonológica, o que daria pistas da automaticidade do processo. Por outro lado, a realização transparente ao código ortográfico, sem monotongação em cenoura, por exemplo, sinaliza o acesso da rota fonológica, ao invés da rota lexical.

Aquino (2011), ao estudar o processo de decodificação na leitura oral, estabeleceu uma tipologia de erros de leitura distribuída em duas categorias: erros influenciados pela variante dialetal e os erros de decodificação. Os dados para a análise compreenderam o processo de leitura oral de um texto, realizada por 30 alunos do $3^{\circ}$ ao $5^{\circ}$ ano do ensino fundamental. Os resultados relativos aos erros decorrentes da variante dialetal mostraram alta ocorrência de fenômenos variáveis da fala na leitura dos alunos, assim como indicaram indícios de uso das duas rotas (fonológica e lexical) nos três anos de escolaridade. Os $3^{\circ}$ e $4^{\circ}$ anos deram preferência à rota fonológica; já no $5^{\circ}$ ano houve indícios de preferência pela rota lexical. A autora enfatiza que os erros influenciados pela variante dialetal do aluno não comprometem a leitura; por outro lado, os erros de decodificação têm uma forte influência na qualidade da leitura do texto e, consequentemente, prejudicam a compreensão (AQUINO, 2011).

Machado (2018) analisou fenômenos variáveis da fala na leitura em voz alta de estudantes do $6^{\circ}$ ano do ensino fundamental; os resultados apontam a transposição de fenômenos variáveis para a leitura em voz alta dos estudantes, sugerindo o uso da rota lexical: "o leitor faz uso de seu repertório linguístico 
para tentar compreender o texto lido, demonstrando ser um leitor proficiente" (MACHADO, 2018, p. 225).

Assumimos que as pistas de acesso à rota lexical permitem verificar a eficiência da leitura. Mesmo estando em um evento de letramento, atividade apoiada em um texto escrito e no qual se espera um estilo monitorado, pelo fato de o leitor acessar automaticamente as palavras em sua memória, é esperado que fenômenos variáveis da fala sejam traspostos para a leitura em voz alta, principalmente os traços graduais, que estão presentes na fala de quase todos os brasileiros: as palavras "três", "cenoura", "comer", podem ser lidas como treys (ditongação), ceno/_Ra (monotongação), come/_/(apagamento do /R/ em coda silábica). A transposição não afeta negativamente a fluência e a compreensão da leitura, ao contrário; pode dar pistas acerca da proficiência em leitura (AQUINO, 2011, MACHADO, 2018).

No entanto, quanto mais distante a variedade dialetal do aprendiz estiver da variedade urbana de prestígio, mais distante da relação transparente com o código ortográfico da língua ensinado pela escola, e, por conseguinte, mais dificuldade ele pode ter para compreender tais regras. Por isso, reitera-se a importância de que ter conhecimento dos fenômenos variáveis na fala das crianças pode ajudar o professor a identificar e abordar com mais acerto problemas de aprendizado na leitura (FLÔRES, 2017).

Neste estudo, propomos a identificação do perfil de leitura dos estudantes, a partir dos parâmetros presença de traços graduais na leitura em voz alta e tempo de leitura. Para validá-lo, comparamos os resultados do perfil de leitura dos estudantes com seu desempenho em um teste padronizado, aos moldes da ANA.

\section{Método}

\section{Escola}

A amostra para esta pesquisa foi constituída em uma escola municipal de São Cristóvão, Sergipe (código INEP28028252). Em 2017, a escola atendeu aproximadamente 605 alunos, 179 dos anos iniciais, $1^{\circ}$ ao $5^{\circ}$ ano, 426 dos anos finais, $6^{\circ}$ ao $9^{\circ}$ ano. Desses, $40 \%$ são oriundos da zona urbana e $60 \%$ da zona rural.O indicador de fluxo relativo a 2017 apontou que, a cada 100 alunos, 30 não foram aprovados, e a taxa de rendimento para os anos iniciais foi de $63,9 \%$ e de 67,5\% para os anos finais. O último Índice de Desenvolvimento da Educação Básica (IDEB) é o de 2015, cujo resultado foi 3,0 (a escola não alcançou a meta projetada, de 3,6). Em 2017, o número de participantes no SAEB foi insuficiente para que os resultados fossem divulgados.Embora a escola tenha participado das três aplicações da Avaliação Nacional da Alfabetização (2013, 2014 e 2016), nos boletins de desempenho por escola disponíveis no site do INEP não constam os resultados referentes ao teste de compreensão em leitura. Entretanto, os níveis de desempenho dos estudantes no município de São Cristóvão, na última avaliação (2016), foram: $64,5 \%$ dos alunos do $3^{\circ}$ ano do ensino fundamental ficaram no 
nível $1 ; 28,8 \%$ no nível $2 ; 7,9 \%$ no nível 3; e apenas $0,8 \%$ no nível 4 , abaixo do cenário estadual, em que 40,3\% dos estudantes estão no nível 1 e 3,3\% no nível 4 .

\section{Participantes}

Os participantes desta pesquisa foram estudantes do $3^{\circ}$ ano do ensino fundamental, do ano de 2017, acompanhados longitudinalmente no período de maio a dezembro. Havia 29 alunos matriculados na turma, porém apenas 22 frequentavam as aulas, 8 meninas e 14 meninos, cujas idades variavam entre 8 e 12 anos $(M=9,5, D P=1,2)$, e apenas 12 não apresentavam distorção idade/ série. Ao final do ano letivo de 2017, somente seis alunos da turma foram aprovados para o ano seguinte.

Dos 22 estudantes que freqüentavam as aulas, 21 participaram da coleta de dados, após consentimento dos pais ou responsáveis e assentimento dos participantes, embora não em todas as etapas da coleta, na medida em que nem sempre todos estavam presentes (Parecer CEP/CONEP/UFS 2.008.797). A não participação de um único estudante ocorreu porque ele esteve ausente nos três dias de desenvolvimento de atividades de coleta de dados.

\section{Etapas de coleta de dados}

Os estudantes participaram de quatro coletas em diferentes momentos, realizadas durante o turno regular das aulas, no período matutino.

Quadro 1 - Cronograma das atividades realizadas

\begin{tabular}{|c|c|}
\hline Data & Atividades \\
\hline Primeira coleta $(10 / 05 / 2017)$ & 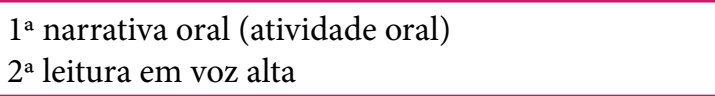 \\
\hline Segunda coleta $(09 / 11 / 2017)$ & $\begin{array}{l}1^{a} \text { entrevista (fala espontânea) } \\
2^{\text {a }} \text { narrativa oral (atividade oral) } \\
3^{\text {a }} \text { leitura em voz alta }\end{array}$ \\
\hline Terceira coleta $(13 / 12 / 2017)$ & $\begin{array}{l}\text { 1' nomeação/descrição de imagens (atividade oral) } \\
3^{\text {a }} \text { leitura em voz alta }\end{array}$ \\
\hline Quarta coleta $(19 / 12 / 2017)$ & Aplicação do TLC \\
\hline
\end{tabular}

Fonte: Elaboração própria.

Os procedimentos de documentação foram realizados em etapas, cada uma correspondendo a um contexto estilístico de maior ou menor monitoramento da fala: fala espontânea $\rightarrow$ atividade oral $\rightarrow$ leitura em voz alta.

Para a documentação da fala espontânea, foram realizadas as gravações de pequenas entrevistas com os alunos individualmente, em sala paralela à classe, em que eles foram instados a contar a sua rotina escolar e o seu dia a dia. A coleta de atividade oral foi realizada em duas ocasiões: em uma, a partir de um suporte visual de história em quadrinhos muda, foram realizadas as gravações dos estudantes, individualmente; a outra atividade oral foi a realização de um ditado 
mudo, com estímulos visuais que os estudantes descreveram/nomearam imagens oralmente. Esta documentação também foi gravada, individualmente.

Figura 1 - Instrumentos de coleta de dados nas atividades orais e de leitura.

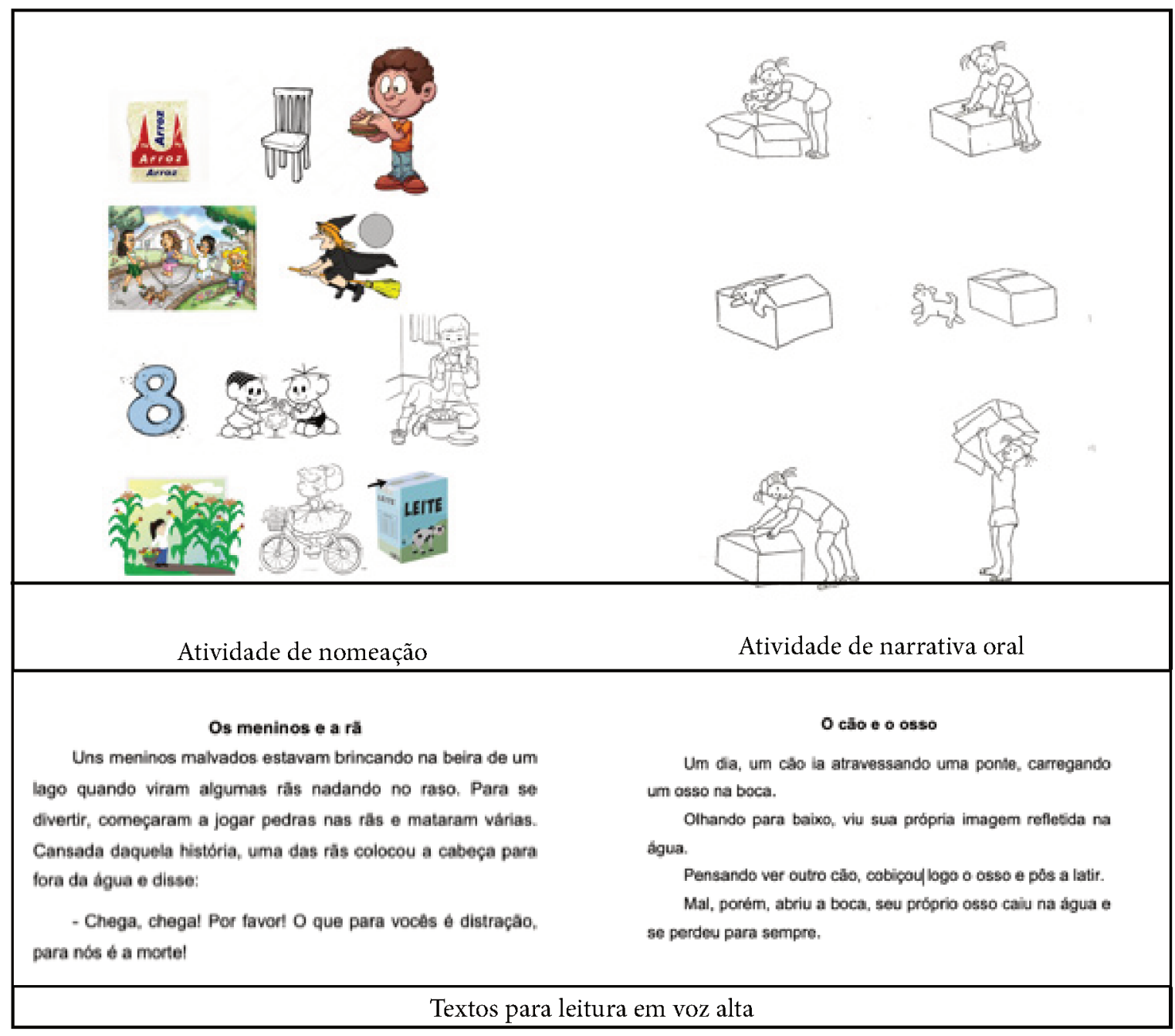

Fonte: elaboração própria.

Os textos para a leitura em voz alta foram extraídos de livros didáticos do $3^{\circ}$ ano do ensino fundamental do Programa Nacional do Livro Didático de 2016. Tanto os textos para a leitura em voz alta como as figuras para a nomeação foram escolhidos em função das palavras que também poderiam possibilitar a ocorrência dos mesmos fenômenos variáveis, como a ditongação e a monotongação.

Por último, aplicamos um teste de compreensão em leitura (TCL) semelhante à ANA de língua portuguesa, disponibilizado pela Editora Moderna (2016). Ao contrário das coletas anteriores, a aplicação do teste foi coletiva e contou com 18 participantes. O TCL contém 17 questões de múltipla escolha e 3 de produção escrita. Todas as habilidades do eixo de leitura da matriz de referência da ANA são contempladas nas questões do teste. Com exceção da habilidade 1, avaliada somente na questão 1, as demais habilidades são avaliadas em duas questões. As questões foram pontuadas com escores atribuídos conforme a matriz de referência. 


\section{Tratamento dos dados}

Toda a documentação linguística das coletas orais foi gravada e transcrita. Codificamos todos os contextos possíveis de ocorrências dos fenômenos variáveis na fala espontânea dos alunos, nas atividades orais e na leitura em voz alta, seguindo os padrões de análise da sociolinguística variacionista (taxa de frequência e análise univariada). Computamos os acertos no TCL para calcular a nota individual de cada participante para a análise da variância entre o tipo de leitura e o desempenho no TLC e a taxa de traços graduais na leitura em voz alta (regressão linear).

\section{Resultados}

\section{Perfil de leitura}

A partir de gravações da leitura em voz alta dos estudantes, identificamos cinco tipos de leitura: não leitura, leitura alfabética, leitura silábica, leitura palavra por palavra e leitura hábil. Dos 21 alunos da turma, quatro não conseguiram realizar as atividades de leitura em voz alta. $\mathrm{O}$ excerto (1) ilustra esta situação.

(1) DOC: você poderia ler esse texto aqui?

LUI: eu não sei ler assim eu não consigo não

DOC: consegue reconhecer aqui essa letra?

LUI: uma bola isso eu não sei

DOC: oh a primeira letra dessa palavra você conhece?

LUI: não sei não

DOC: e essa daqui olhe ((RUÍDO))

LUI: bola

DOC: sabe que letra é essa? essa?

LUI: bola

DOC: e aqui?

LUI: sei não

DOC: e essa letra você conhece?

LUI: não

DOC: por exemplo essa palavra aqui olhe você conhece?

LUI: não

Quando o documentador de campo apontou para o título do texto e perguntou reconhecia a primeira letra, a aluna disse que era uma bola, para a letra $c$ da palavra cão; depois afirmou que não sabia. Nas duas últimas letras também da palavra cão, a aluna continuou dizendo que era uma "bola". Por este comportamento, presumimos que a aluna ainda não chegou à fase pré-alfabética (EHRI, 1995), esperada para nível anterior ao $3^{\circ}$ ano do ensino fundamental, e suas habilidades de leitura se resumem a comparar as letras $a$ e $o$ a um objeto. 
DOC: você sabe ler?

FLA: um pouco só

DOC: vamos lá né vamos lá tentar bom por exemplo pegando aqui olhe ((RUÍDO)) você poderia ir lendo o que você consegue e eu vou acompa nhando aqui?

FLA: o... cê... dê... e... fê... guê... agá... i... jota... cá... lê... como é o nome dessa letra mesmo?

DOC: leia só o que você souber

FLA: aqui é ene né? aqui né i?

DOC: leia só o que você souber o que você não souber você pode pular FLA: a... be... cê... dê... e... fê...gue... agá... i...i... i... jota... u... ((RUÍDO))

u... xi... fa...

DOC: você reconhece essa letra?

FLA: é um ene? um pe?

Embora no início tenha dado pistas de que conhecia o sistema alfabético, nomeando cada letra das palavras do texto, o... cê...., em (2), após alguns segundos de pausa, o aluno começou a falar a sequência do nome das letras do alfabeto. Depois, apontou para uma das palavras do texto e perguntou que letra era aquela. Não obtendo a resposta por parte do documentador, prosseguiu dizendo os nomes das letras mais uma vez na ordem alfabética, agora começando pela letra $a$. O documentador volta para o título do texto, O cão e o osso (figura 1), e pergunta para o aluno se ele reconhecia a primeira letra, a criança questiona: é um ene? um pê? O aluno memorizou a sequência do nome das letras do alfabeto, porém, quando tais letras não estão na ordem, ele nos deu pistas de que não consegue reconhecê-las.

Estes dois alunos, assim como os demais classificados como em situação de não leitura, ainda não atingiram o conhecimento do princípio alfabético, primeira condição necessária para a aprendizagem inicial da leitura (MORAIS et al., 2013).

Classificamos como na fase pré-alfabética (EHRI, 1995) os seis alunos que reconhecem apenas as letras ou algumas delas.

$$
\begin{aligned}
& \text { ALI: Ó... ca... a... ó... caua... é ó... ó... cê... cê... ó... } \\
& \text { U... nê... dê... i... a...u... nê... ca... ó...ca... ((RUÍDO)) aó...ia... a... tê... rê... } \\
& \text { a... vê... é...cê... cề... a... nê... dê... ó... u... nê... a... ((RUİDO)) pê... ó... nê... } \\
& \text { tê... ca...rê... rê.... ((RUÍDO)) é... guê... a...nê... dê... ó... u... nê.... ó... cê... cê... } \\
& \text { ó... nê... a... be... ó... ó... ca... } \\
& \text { Ó... lê... guê... a... nê... dê... ó... pê... a...rê... a... bê... a... i... xis... ó... vê... iu... } \\
& \text { cê... u... a... pe... rê... o... pê... rêe... i... a... i... nê... a... guê... é... nê... rê... é... } \\
& f-f-f o \ldots v i \ldots \text { ê... tê... nê... a...a... guê... u... a... } \\
& \text { Pê... é... nê... cêe... a... nê... dê... o... vê... é... rê... ó... u... tề... rê... ó... ca... ca.. } \\
& \text { ó... cê. ó, bê, i, cê, ó, u... lê, lê... ó... guê... ó... ó... cê... cê... ó...é... pê... ó... } \\
& \text { cê...a... lê... a... tê... i i... rê... } \\
& \text { Nê.. a... lê... pê... rê... é... né... a... bê... rê... iu... a... bê... ó... ca... cê.. u... ó... }
\end{aligned}
$$


cê... cề... ó... cê... a... iu... nê... a... guê... u... a... é... cê... pê... rê... dê... u... pê...

a... rê... a... cê... é... nê... pê... rê.

Ao ler o texto $O$ cão e o osso, em (3), o aluno nomeia cada letra que compõe as palavras do texto. No início, ainda no título, houve a tentativa de ler a palavra cão; porém o aluno não conseguiu, mesmo sendo um monossílabo. $\mathrm{O}$ aluno ainda estava no nível do nome das letras, inclusive, ainda confundia o nome de algumas, por exemplo, nas palavras que têm a letra $m$, soletrava nê: uma u...nê... a..., imagem $\sim i \ldots n \hat{e} \ldots . . . . . g u \hat{e} . . . e ́ \ldots . . n \hat{e} \ldots .$, a letra $s$, soletrava como $c \hat{e}:$ osso $\sim$ ó... cê... cê... ó..., a letra $h$, como guê: Olhando Ó... lê... guê... a... nê... dê... ó...

Ao contrário do estudante do excerto (3), que soletrou as letras que formam cada palavra do texto, demonstrando não conhecer o nome de apenas algumas, o estudante do excerto (4), em atividade de leitura em voz alta, disse somente o nome das letras referentes às vogais e a algumas consoantes:

(4) LUC: eu não conheço todas as letra não

DOC: diga só as que você souber

LUC: u... dê... i... a... u... a... o... i... a... a... tê... a... é... a... dê... u... a... tê...

cê... a... é... guêe... a... dê... o... u... o... o... a... bê... cê... a...

A compreensão do princípio alfabético e do princípio de correspondência entre grafemas e fonemas são habilidades que, no $3^{\circ}$ ano do ensino fundamental, já deveriam estar consolidadas; este tipo de leitura não corresponde ao que se espera de habilidades nesta etapa de escolarização.

A leitura silábica equivale à fase alfabética inicial (EHRI, 1995) e é caracterizada pelos alunos que leem sílaba por sílaba das palavras, apresentam dificuldades e despendem esforços para entender algumas sílabas, por isso, decodificam lentamente e cometem muitos erros de decodificação. Na turma do $3^{\circ}$ ano, identificamos seis alunos com este perfil.

(5) ANG: Ó c-é-ues- táca-in- in- do

E-raera néumavera umaga-lin-éle.. i... na... né?lin-auma galinha né quea sã- ãs-dó vovê a néda- vadavasi- ca- dosi- ca-sico-ciscando né?é isbo isxo né?

DOC: pode continuando

ANG: aqui né? daqui né?

ANG: ((RUÍDO)) deaqui nébodeuma ju- ju-ju- nã- ja- nãoumaja-bu-tica-da- jabutica-be-bê-i- ro né tá certo?

DOC: ((RUÍDO)) continue

ANG: aqui né que o a- qua- quê u a ene quan- to quanto uma ju- lé- jabu- ti- ca- di- bi- bi-bin-ó binhoné?eis-co-caescolané?ca-ehca-i- ucaiu bêébê aqui é um eme né?bê...ê... vou ler mais não. 
Em (5), foram poucas as palavras do texto decodificadas corretamente: o céu está caindo, era, galinha, ciscando, na primeira frase o leitor aprendiz lê sílaba por sílaba e não retoma a fim de conferir quais eram as palavras, como acontece com em era, galinha e ciscando, nestas, a criança lê sílaba por sílaba, titubeia em algumas, mesmo assim, em seguida, retoma e lê a palavra inteira. Há maior demanda de tempo por parte do leitor para identificar algumas letras e sílabas, principalmente em vocábulos de maior extensão. Uma característica comum a este tipo de leitor é a insegurança no reconhecimento de letras e sílabas, como podemos observar no excerto (5), quando o aluno tenta ler a palavra ciscando, baixo, sica-do si-ca-sico-ciscando né? é is boi s xo né? A todo o momento, o aluno solicita auxílio do documentador para ter certeza de que estava lendo corretamente.

Dois alunos da turma realizaram a leitura do tipo palavra por palavra, equivalente à fase alfabética intermediária (EHRI, 1995), identificada por meio das sistemáticas pausas entre uma palavra e outra. Diferentemente dos tipos de leitura anteriores, os alunos deste perfil leem a palavra inteira e não sílaba por sílaba, embora em algumas palavras a leitura ainda seja silábica, decodificaram com poucos erros e reconheceram muitas palavras automaticamente.

(6) CAL: O são e osso... um dia... um cão... ai ia... atravessando... uma... ponte.... carregando... um osso... na boca... olha- olhando para... baixo... viu sua... (propria) própria... imagem... refletida... na ((RUÍDO)) água... pensando... ver... outro... cão... condições (né) (logo)...oss- osso... e... pôs... a... latir...mal porém... a- briu... a boca... seu... pro- pró- prio osso...caiu na... água... e se... perdeu...para... sempre...

Em (6), o aluno inicia a leitura do texto cometendo um erro de codificação, lê a palavra cão como são. No entanto, em seguida lê a mesma palavra sem erro de decodificação, há pausas entre uma palavra e outra, porém quando há duas monossílabas que estão próximas, ele lê sem pausas. Os alunos que apresentam a leitura palavra por palavra já alcançaram as duas primeiras condições da aprendizagem inicial da leitura, o conhecimento do princípio alfabético, relação grafema-fonema, e demonstram progresso no conhecimento do código ortográfico e domínio dos procedimentos de decodificação na leitura (MORAIS et al, 2013).

Na leitura hábil, equivalente à fase alfabética consolidada (EHRI, 1995), os alunos, diante de textos adequados ao seu nível de escolaridade, ativam de modo inconsciente e automático as representações ortográficas e fonológicas das palavras (Morais, 2014).

BRU: O cão e o osso

Um dia um cão ia atravessando uma ponte... carregando um osso na boca... olhou para baixo... viu sua própria imagem refletida na água... pensando ver outro cão $($ ) ( ) o-ossoe pôs a latir... mal porém abriu a boca... seu próprio osso caiu na água e se perdeu para sempre. 
A leitura realizada pelo leitor hábil, ao contrário dos outros tipos de leitura, é feita por blocos de palavras, reconhece as palavras como constituintes de uma sentença, sem nenhum ou pouco embaraço, há algum ritmo, sem gaguejar, os erros são compatíveis com o nível de escolaridade do estudante. Leitores deste perfil são os que têm mais possibilidade de compreender o que leem. Na turma sob análise, apenas três estudantes atingiram esse perfil de leitura.

\section{Desempenho no TCL}

A análise do perfil dos leitores a partir da leitura em voz alta apontou o predomínio dos estudantes no nível alfabético e silábico, além de quatro estudantes que não conseguiram realizar a tarefa de leitura (Figura 2). Já a análise da distribuição dos escores obtidos no TCL quanto aos perfis de leitura possibilita identificar dois grupos: o grupo dos leitores no nível alfabético $(\mathrm{m}=361 \mathrm{dp}=160) \mathrm{e}$ silábico $(\mathrm{m}=291, \mathrm{dp}=152)$, e os leitores no nível palavra por palavra $(\mathrm{m}=594$, $\mathrm{dp}=26,3)$ e hábil $(\mathrm{m}=584, \mathrm{dp}=136)$.

Figura 2 - Distribuição dos tipos de leitor e do escores dos participantes quanto ao tipo de leitura.
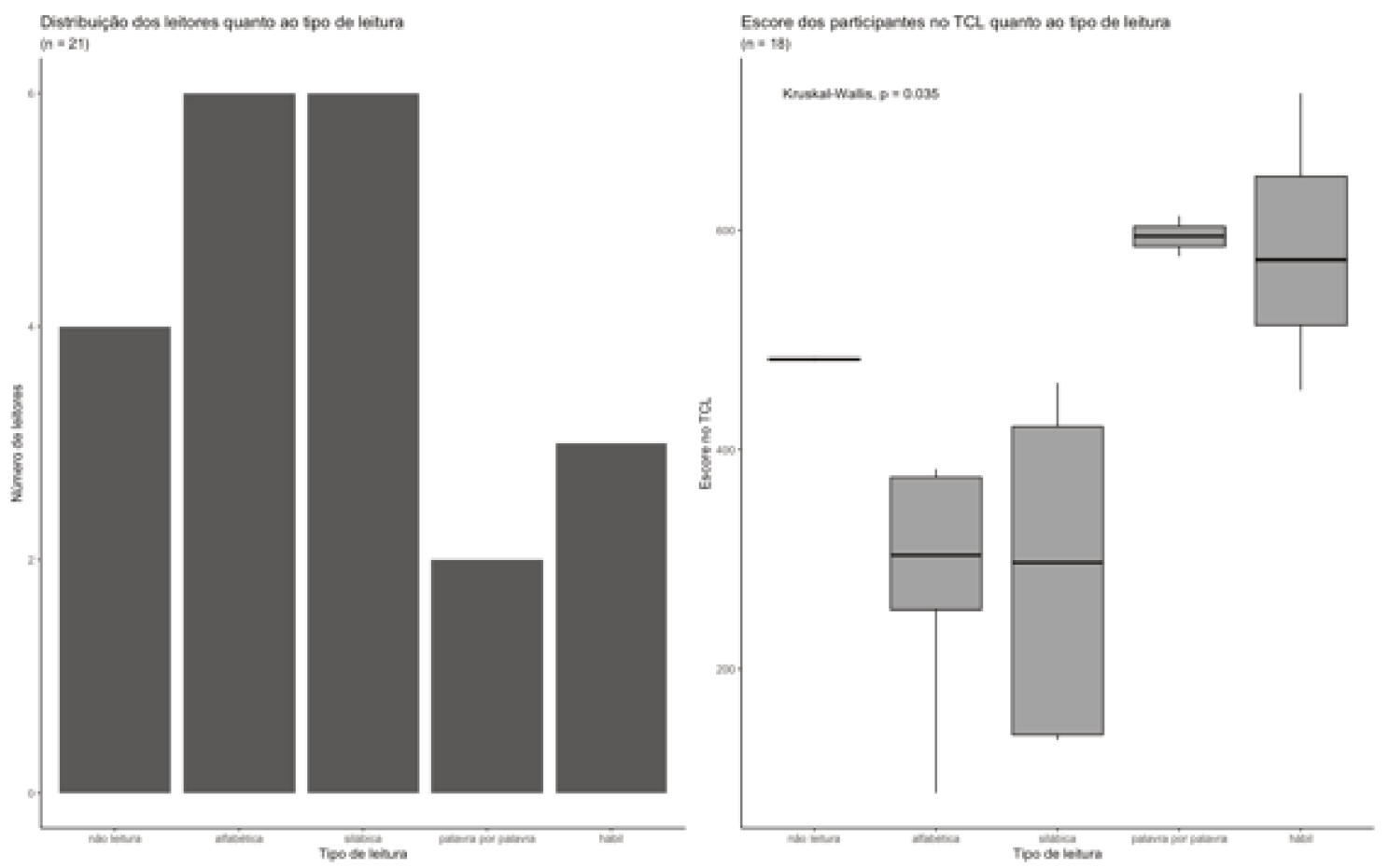

Fonte: elaboração própria.

Considerando a relação entre as fases de leitura (EHRI, 1995) e as rotas de leitura (COLTHEART, 2013), os alunos que realizam a leitura alfabética ou silábica podem ou não ter acesso à rota fonológica, e ainda não têm acesso à rota lexical (Figura 3), pois: 
1. ainda não desenvolveram a consciência fonológica e não conhecem o princípio do sistema alfabético, responsável por introduzir gradativamente o leitor aprendiz no domínio do sistema de escrita;

2. conhecem as letras apenas pelos seus respectivos nomes e por isso têm dificuldade em estabelecer relação entre unidades sonoras e suas representações gráficas, principalmente nas correspondências grafema-fonema com mais de uma correspondência sonora;

3. realizam leitura silábica, decodificam lentamente, têm dificuldade para entender a palavra (neste caso, o aluno ainda não faz uso nem da rota fonológica, pois não desenvolveu condições para isso).

Figura 3 - Relação entre rotas e tipos de leitura.

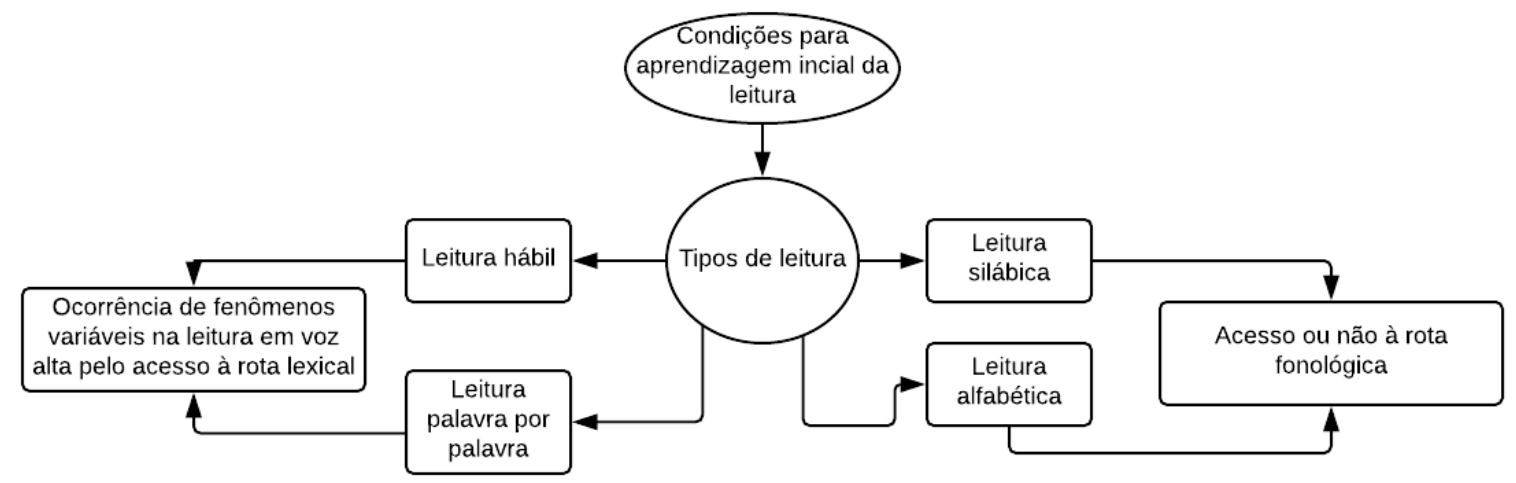

Fonte: elaboração própria.

Por outro lado, os alunos que alcançaram os tipos de leitura hábil e palavra por palavra são aqueles cujo processo de decodificação foi automatizado, logo podem fazer mais uso da rota lexical, o que pode ser evidenciado pela transposição de fenômenos variáveis da fala para a leitura em voz alta, dando, inclusive, pistas acerca da sua compreensão leitora. Esperamos encontrar nestes tipos de leitura as maiores taxas de ocorrência de traços variáveis graduais da fala que passam para a leitura.

\section{Traços variáveis da fala na leitura}

A leitura em voz alta é um dos melhores meios para identificar os procedimentos de leitura de uma criança, "os erros sistemáticos de decodificação dão boas indicações sobre as dificuldades apresentadas pelo texto para diferentes crianças, em todos os níveis (compreensão textual, conhecimento do léxico, domínio do código etc.)" (CHARTIER, 2007, p. 180). A partir da leitura em voz alta, podemos verificar quais condições da aprendizagem inicial da leitura as crianças 
já dominam, qual o seu tipo de leitura e quanto tempo elas levam para ler textos escritos adequados ao seu nível de escolaridade.

Verificamos a ocorrência de quatro fenômenos fonológicos variáveis que, a depender do tipo de leitor, podem ser transpostos para a leitura em voz alta, nos dando pistas acerca da rota de leitura acessada, e de compreensão leitora. Os fenômenos controlados foram a monotongação, a ditongação, a realização do /R/ em coda silábica e a realização da lateral palatal (Figura 4).

Figura 4 - Análise univariada dos fenômenos sociolinguísticos quanto ao gradiente estilístico.
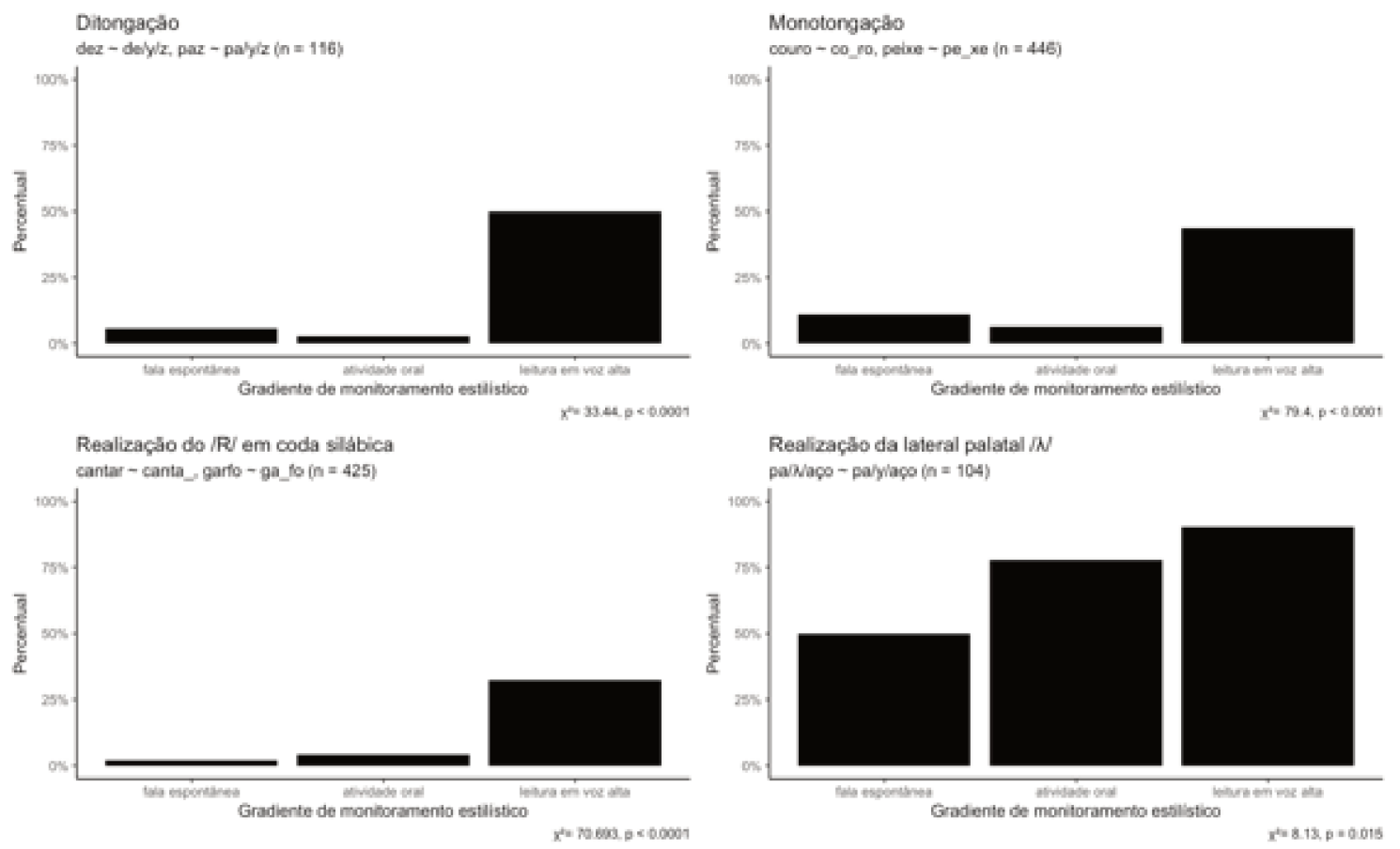

Fonte: elaboração própria.

A monotongação consiste na redução da semivogal dos ditongos, sejam eles crescentes (negócio negoçu, polícia poliça, indivíduo individu, espécie $\sim$ especi), decrescentes (caixa $\sim$ caxa, ameixa $\sim$ amexa, cenoura $\sim$ cenora) ou nasais (pegaram $\sim$ pegaru, ontem onti). Araújo e Borges (2018) realizaram um teste de percepção que aponta que, tendo consciência ou não da redução da semivogal no ditongo decrescente, os falantes apresentam posicionamento positivo quanto ao fenômeno e acreditam que ele acontece independentemente de a pessoa ser escolarizada ou não. Já o mesmo não acontece com a redução no ditongo crescente: os estudantes têm uma visão negativa desse fenômeno e acreditam que as pessoas podem sofrer alguma coerção social, corroborando, assim, os resultados dos estudos sociolinguísticos de que os fenômenos mais salientes são os mais estigmatizados.

Machado (2018) observou o mesmo fenômeno com dados da leitura oral e identificou em seus resultados a monotongação na leitura em voz alta de alunos do $6^{\circ}$ ano. A monotongação foi recorrente nos três gradientes de monitoramento 
estilístico; por se tratar de um fenômeno não estigmatizado, na fala espontânea e nas atividades orais, o ditongo decrescente /ow/ teve ocorrência categórica, enquanto os ditongos/ay/ e /ey/ tiveram ocorrência quase categórica; podemos dizer que, na leitura em voz alta, diante dos contextos linguísticos com possibilidades de ocorrências da monotongação, os leitores proficientes acessam a rota lexical.

Enquanto na monotongação há o apagamento da semivogal nos ditongos, a ditongação é a transformação de uma vogal em ditongo, nas sílabas travadas por /S/ é acrescentado um glide anterior /y/ em palavras terminadas em /e/ e /a/: mês $\sim m e / \mathrm{y} / \mathrm{s}, \mathrm{mas} \sim \mathrm{ma} / \mathrm{y} / \mathrm{s}$, através $\sim$ atrave/y/s. O nível ou registro que mais favorece a ditongação é o coloquial, informal, familiar, mesmo com falantes de maior escolarização (BORTONI-RICARDO, 2004). No estudo de Aquino (2011), com dados de leitura em voz alta de alunos do $3^{\circ}$ ao $5^{\circ}$ anos, os estudantes mais escolarizados, ou seja, os do $5^{\circ}$ ano foram aqueles que mais usaram a forma ditongada, o que nos dá suporte para nossa hipótese de que a realização deste tipo de fenômeno na leitura em voz alta seja uma pista de acesso à rota lexical, e por conseguinte, configure maior automaticidade na decodificação e indício de compreensão.

De acordo com a distribuição percentual de ocorrências nos três gradientes de monitoramento estilísticos, a ditongação foi quase categórica tanto na fala espontânea $(27,5 \%)$ quanto nas atividades orais $(28,5 \%)$. Já na leitura em voz alta, o percentual de não ocorrência foi superior ao de ocorrências (46\%).

Assim, quando ocorre na leitura a ditongação, mais do que a monotongação, dá pistas de um tipo de leitor que irá ter sucesso nos testes.

A não realização do /R/ é um fenômeno recorrente na maioria dos dialetos brasileiros, assim como em todos os extratos sociais (BORTONI-RICARDO, 2004). Pinheiro et al. (2017) e Machado (2018) verificaram a recorrência do fenômeno na leitura em voz alta de alunos do ensino fundamental.

A realização do $/ \mathrm{R} /$ em coda silábica foi verificada nas posições no meio (coda interna, como em garfo, sorvete, árvore) e no final das palavras (coda externa, como em brincar, comer, mulher, qualquer), e nas classes gramaticais dos verbos e não verbos, seguindo as tendências de condicionamento linguístico identificadas em estudos anteriores (MONARETTO, 2000, MOLLICA; FERNANDEZ, 2003, GOMES, 2006).

Em relação ao gradiente de monitoramento estilístico, os alunos realizaram mais o apagamento do $/ \mathrm{R} /$ em coda silábica no gradiente de fala espontânea, com $2 \%$ de realização do $/ \mathrm{R} /$, seguido do de atividade oral (4\%); já na leitura em voz alta, a taxa de realização foi mais alta, com $29 \%$. Estes resultados seguem as tendências encontradas em outros estudos para o mesmo fenômeno que comparam fala e leitura (FARIAS; OLIVEIRA, 2013, PINHEIRO et al, 2017).

Enquanto os traços variáveis anteriores são graduais no português brasileiro (apresentam distribuição que não sofre condicionamento de escolarização ou

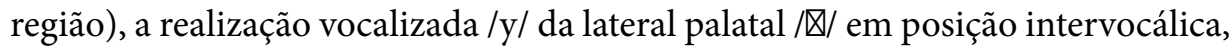
como em coe/ $\varangle / o \sim \operatorname{coe} / y / o$ é um traço descontínuo, passível de estigmatização, por ser associado a áreas não urbanas e à não escolarização. Em um estudo sobre a transposição da fala para a escrita do fenômeno da vocalização em estudantes 
do ensino fundamental menor, Freitag (2011) verificou que com o avanço da escolarização, a variante de prestígio, a realização lateral palatal, tende a ser utilizada. Os resultados na amostra apontam que quanto maior o monitoramento no gradiente estilístico, maior a realização da forma de prestígio. No entanto, diferentemente dos traços graduais, a realização de prestígio já tem uma taxa de realização alta, mesmo na situação de fala, o que reforça o estigma associado ao traço, e também evidencia a consiência sociolinguística dos estudantes.

A análise da ocorrência de traços graduais e descontínuos em um gradiente de monitoramento estilístico evidencia que os alunos que têm consciência sociolinguística transpõem a variante consolidada na fala espontânea e nas atividades orais para a sua leitura em voz alta,mostrando automaticidade no processo de decodificação do texto lido, ao acessar a rota lexical, a partir do reconhecimento visual das palavras escritas, o leitor procura em seu léxico mental o conhecimento sobre a grafia e a pronúncia da palavra e lê em voz alta como pronuncia em sua fala espontânea (COLTHEART, 2013, AQUINO, 2011, MACHADO, 2018).

\section{Desempenho em leitura e variação linguística}

A fim de verificar se os estudantes que têm consciência sociolinguística, ou seja, que transpõem traços graduais da fala para a leitura, têm melhor resultado no TLC, realizamos análises de regressão entre a taxa de aplicação de cada um dos quatro fenômenos variáveis anteriores na leitura em voz alta e os escores obtidos pelos estudantes no TLC (Figura 5).

Figura 5 - Regressão entre as taxas de ocorrência dos fenômenos sociolinguísticos e o desempenho no TLC $(n=18)$
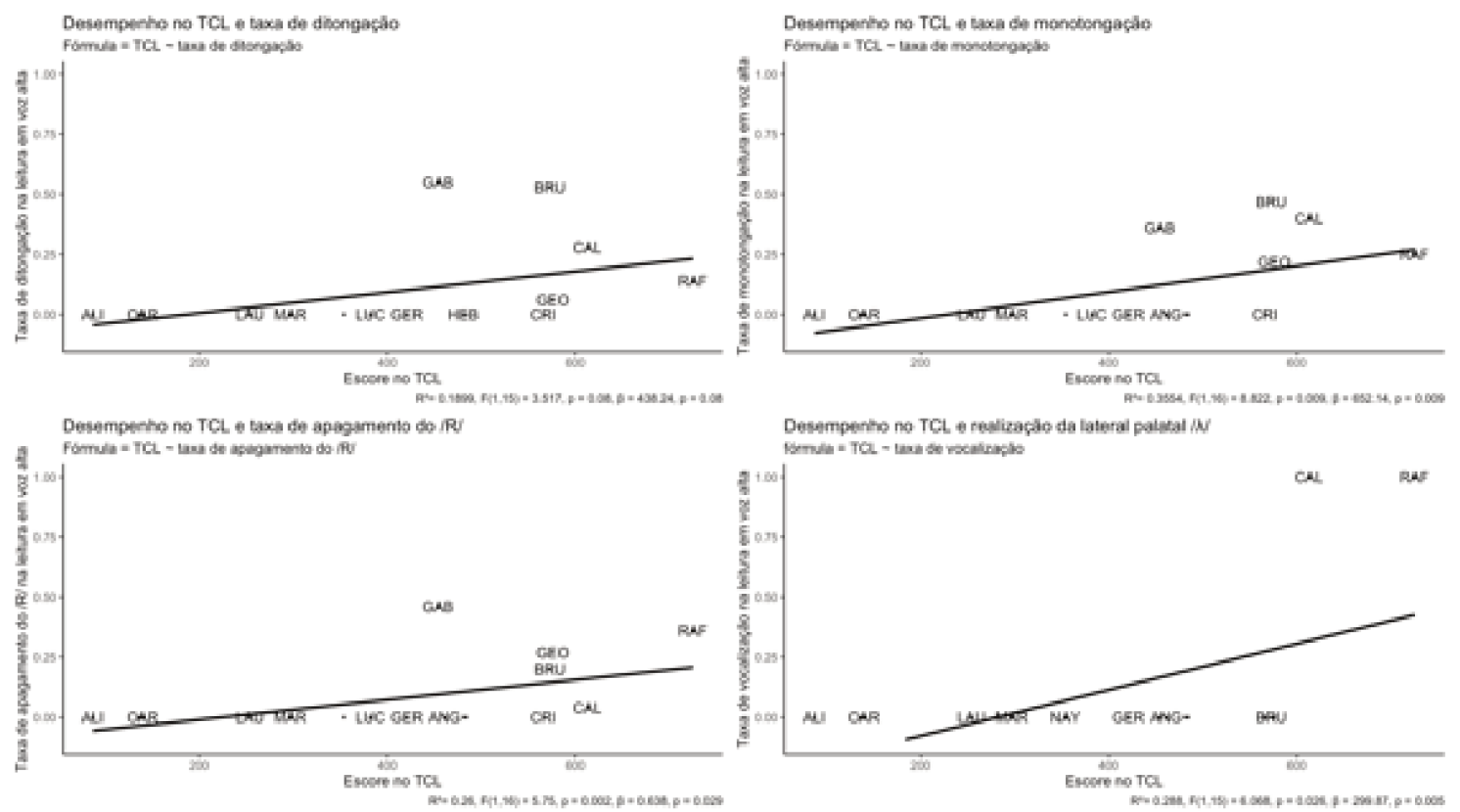

Fonte: elaboração própria. 
Nos gráficos da figura 5, em todos os fenômenos variáveis controlados, a regressão entre a taxa de ocorrência do fenômeno da fala na leitura em voz alta (ditongação, monotongação, vocalização e apagamento do R) e o escore no TCL aponta relação positiva, com a reta ascendente.

Observamos que os alunos que apresentam as maiores taxas de realização dos fenômenos variáveis na leitura em voz alta sistematicamente são os alunos que apresentam os tipos de leitura considerados adequados/desejáveis para a série: GAB, BRU e RAF apresentam leitura hábil, e CAL e GEO apresentam leitura palavra por palavra. O cotejo entre o perfil de leitura identificado e a relação entre desempenho no TLC e a ocorrência de traços variáveis da fala evidencia que a leitura em voz alta que apresenta traços variáveis da fala não pode ser considerada "imprecisa"; ao contrário, estes traços ocorreram somente na leitura hábil e palavra por palavra, e por estudantes que atingem o nível esperado no TLC.

\section{Conclusão}

Constatamos que os estudantes com perfis de leitura hábil e palavra por palavra são os que tiveram melhor desempenho no TCL e são os que realizam mais traços variáveis da fala na sua leitura em voz alta, sugerindo uma relação entre consciência sociolinguística e sucesso na aprendizagem inicial da leitura.

A sensibilidade sociolinguística aos fenômenos graduais e descontínuos do português brasileiro e a sua transposição para a leitura em voz alta podem nos dar pistas do sucesso em leitura. Ao observar os traços variáveis da fala passando para a leitura, o professor, a partir do diagnóstico em sala de aula, nas suas práticas cotidianas, pode intervir no processo, para reduzir as assimetrias identificadas nos testes em larga escala. A sensibilização do professor-alfabetizador à dimensão variável pode auxiliar na transição das rotas de leitura, levando ao sucesso no aprendizado inicial da leitura. E, com treinamento sociolinguístico, a partir da leitura em voz alta, o professor pode avaliar o tipo de leitura de seus estudantes continuamente, durante todo o ano letivo, e não depender do resultado de uma avaliação externa, que não chega a tempo para a intervenção pedagógica e redução de assimetrias de aprendizagem.

\section{Referências}

AQUINO, M. F. S. Uma proposta de tipologia de "erros" de leitura: análise sociolinguística e cognitiva. 2011. Tese (Doutorado em Linguística). Universidade Federal da Paraíba, João Pessoa, 2011.

ARAUJO, A. S.; BORGES, D. K. V. Atitudes linguísticas de estudantes universitários: o fenômeno da monotongação em foco. Tabuleiro de Letras, v. 12, n. 2, p.97-113, 2018.

BORTONI-RICARDO, S. M.Educação em língua materna: a sociolinguística na sala de aula. São Paulo: Parábola, 2004.

BRASIL. Ministério da Educação. Base Nacional Comum Curricular. Brasília, 2017.

BRASIL. Ministério da Educação. Parâmetros Curriculares Nacionais.Ensino Fundamental: Terceiro e Quartos Ciclos:Língua Portuguesa. Brasília, 2000. 
BUCHWEITZ, A.; MOTA; M.; NAME, C. Linguagem: das primeiras palavras à leitura. In R. LENT, R.; BUCHWEITZ, A.; MOTA,M. (Ed.). Ciência para educação: uma ponte entre dois mundos. São Paulo: Atheneu, 2018, p. 119-132.

CHARTIER, A. M. Práticas de leitura e escrita: história e atualidade. Belo Horizonte: Autêntica, 2007.

COLTHEART, M. Modelando a leitura: a abordagem da dupla rota. In: HULME, J. (Ed). A Ciência da Leitura. Porto Alegre: Penso, 2013, p.24-41.

DEHAENE, S. Os neurônios da leitura. Porto Alegre: Penso, 2012.

EHRI, L. C. Orthographic mapping in the acquisition of sight word reading, spelling memory, and vocabulary learning. Scientific Studies of Reading, v. 18, n. 1, p. 5-21, 2014.

EHRI, L. C. Phases of development in learning to read words by sight. Journal of Research in Reading, v. 18, n. 2, p. 116-125, 1995.

FARIAS, A.; OLIVEIRA, I. O apagamento do rótico no português brasileiro e no português europeu: o lido e o dito. In: Anais do Colóquio Brasileiro de Prosódia da Fala, n. 2, 2013, p.1-4.

FLÔRES, O. C. Ensino de leitura e sistema de escrita. Revista linguagem \& ensino, v. 20, n.1, 105-125, 2017.

FREITAG, R. M. K. Entre a teoria e a prática: a Provinha Brasil e o tratamento da variação linguística na alfabetização. Interfaces científicas-educação, v. 3, n. 3, 4354, 2015.

FREITAG, R. M. K. Implicações da variação na alfabetização: a lateral palatal e seus correspondentes grafêmicos. Leitura, v. 2, n. 46, p. 37-56, 2011.

FRITH, U. et al. Beneath the surface of developmental dyslexia. Surface dyslexia, v. 32, p. 301-330, 1985.

FUCHS, L. S et al. Oral reading fluency as an indicator of reading competence: A theoretical, empirical, and historical analysis. Scientific studies of reading, v. 5, n. 3, 239-256, 2001.

GOMES, C. A. Aquisição do tipo silábico CV (r) no português brasileiro. Scripta, v. 10, n. 18, p. 77-90, 2006.

LABERGE, D.; SAMUELS, S. J. Toward a theory of automatic information processing in reading. Cognitive psychology, n. 6, v. 2, p. 293-323, 1974.

LABOV, W. Language in the inner city: Studies in the Black English vernacular. Pennsylvania, University of Pennsylvania Press, 1972.

LABOV, W. When ordinary children fail to read. Reading research quarterly, v.38, n.1, p. 128-131, 2003.

MACHADO, A. P. G. Variação linguística e leitura: fenômenos variáveis da fala na leitura em voz alta. A Cor das letras, v. 19, n. 4, p. 196-218, 2018.

MACHADO, A. P. G.; FREITAG, R. M. K. Pistas de processos de decodificação que levam à compreensão da leitura. Letras de hoje, v. 54, n. 1, 2019.

MODERNA. Simulado para monitoramento da aprendizagem. Avaliação Nacional da Alfabetização, Língua Portuguesa. Caderno do Aluno. Editora Moderna: São Paulo, 2016.

MOLLICA, M. C. M.; FERNANDEZ, C. M. Um caso de estabilidade fonológica comprovado em tempo aparente e em tempo real. Revista de Letras, n. 1, v. 25, p. 94-98, 2003. 
MONARETTO, V. N. O. O apagamento da vibrante pós-vocálica nas capitais da fala do sul do Brasil. Letras de Hoje, n. 35, v.1, p. 275-284, 2000.

MORAIS, J. Criar leitores para uma sociedade democrática. Signo, v. 38, p. 2-28, 2013.

MORAIS, J.; LEITE, I.; KOLINSKY, R. Entre a pré-leitura e a leitura hábil: Condições e patamares da aprendizagem. In: MALUF, M. R.; CARDOSO-MARTINS (Ed.) Alfabetização no século XXI: Como se aprende a ler e a escrever. Porto Alegre, Penso Editora, 2013, p. 17-48.

PINHEIRO, A. M. V.; CUNHA, C. R. D.; LÚCIO, P. S. Tarefa de leitura de palavras em voz alta: uma proposta de análise dos erros. Revista portuguesa de educação, v. 21, n. 2, p. 115-138, 2008.

PINHEIRO, B. F. M., et al. Processos fonológicos que passam da fala para a leitura. In: AZEVEDO, I.; ROIPHE, A. (Ed.). Leitura, escrita e literatura: interseções e convergências. São Cristóvão, EdUFS, 2017, p.10-25.

RASINSKI, T. Creating fluent readers. Educational leadership, v. 61, n. 6, p. 46-51, 2004.

SAMUELS, S. J. Decoding and automaticity: Helping poor readers become automatic at word recognition. The reading teacher, v. 41, n. 8, p. 756, 1988.

SCHNEIDER, W.; CHEIN, J. M. Controlled \& automatic processing: behavior, theory, and biological mechanisms. Cognitive science, v. 27, n. 3, p. 525-559, 2003.

SEIDENBERG, M. S.; MCCLELLAND, J. L. A distributed, developmental model of word recognition and naming. Psychological review, v. 96, n. 4, p. 523, 1989.

SHIFFRIN, R. M.; SCHNEIDER, W. Controlled and automatic human information processing: II. Perceptual learning, automatic attending and a general theory. Psychological review, v. 84, n. 2, p. 127-190, 1977.

Recebido em: 10/03/2019

Aceito em: 28/07/2019 